\title{
Pediatrics Iron deficiency anemia from diagnosis to treatment
}

\author{
Abdulrahman Mohammed Aladhadhi ${ }^{1}$, Saoud Tariq Etaiwi ${ }^{2}$, Khalid Mohammed Alqahtani ${ }^{1}$, \\ Ali Ahmed Bajafar ${ }^{1}$, Ahela Faisal Nono ${ }^{3}$, Sara Edrees Aldrees ${ }^{4}$, Saleh Mohammed Almutawa \\ ${ }^{1}$, Shroq Abdulkreem alghraibi ${ }^{5}$
}

\author{
1 King Khalid University, 2 Medical University of Gdansk, 3 Ibn Sina National College, 4 King \\ Faisal University, 5 Umm al-Qura University
}

\begin{abstract}
:
Aim: the significant points in diagnosis and treatment of iron deficiency which is one of the most common diseases observed in children have been compiled in terms of directing pediatricians, the recent studies performed in this area have been reviewed and the experiences of our center have been explained. Methods: Medline and PubMed database searches were performed for articles about acute cholangitis published in English up to September 2018. Results: iron deficiency anemia continues to be a considerable public health issue worldwide. The major concepts in treatment of iron deficiency anemia consist of making the diagnosis, investigating the condition which triggers to iron deficiency and removal of this problem, replacement of deficiency, enhancement of nutrition and education of patients and families. Conclusion: The serum ferritin level is the best indicator of the iron stores in the body and the first biochemical variable to change in ID.
\end{abstract}

Key words: Pediatrics, Iron deficiency anemia, diagnosis, treatment

\section{Introduction:}

Iron deficiency is the most usual dietary deficiency worldwide and a vital public health issue especially in developing countries. There is no clear information regarding how many individuals are affected by iron deficiency worldwide, but it is estimated that ID is present in a lot of the pre-school youngsters and expectant females in developing nations and in at the very least $30-40 \%$ in industrialized countries when anemia is made use of as an indirect indicator of ID ${ }^{[1]}$. Inning accordance with the 2001 World health Organization (WHO) data, $30 \%$ of the children matured in between 0 and 4 years and $48 \%$ of the children aged in between 5 and 14 years are anemic in establishing countries ${ }^{[1]}$. In our nation, the regularity of iron deficiency anemia (IDA) has been reported to array in between $15.2 \%$ and $62.5 \%$ in different studies performed with youngsters ${ }^{[2-4]}$.

Since anemia is the most crucial indicator of iron shortage, the terms ID and IDA are commonly utilized reciprocally. Nevertheless, iron deficiency might establish in the absence of anemia and the tissues could be impacted from this problem. Iron deficiency appears in different phases. If iron requirement is below intake, iron stores are reduced primarily. After the iron stores are minimized, hemoglobin levels may stay typical for a while which means that iron shortage is observed in the absence of anemia. Right now, only plasma ferritin level and plasma transferrin saturation are decreased. Negative iron equilibrium which proceeds after iron stores are tired appears with decreased hemoglobin. Conclusively, reduced body iron shops have been defined as ID and worsening of this problem and growth of anemia is specified as IDA.

In this article, the significant points in diagnosis and treatment of iron deficiency which is one of the most common diseases observed in children have been compiled in terms of directing pediatricians, the recent studies performed in this area have been reviewed and the experiences of our center have been explained.

\section{Methodology:}

Medline and PubMed database searches were performed for articles about acute cholangitis published in English up to September 2018. The keyword search headings included "Iron deficiency anemia" and 'anemia', and a combination of these was used. References list of each included study were searched for further supportive data.

\section{Discussion:}

- Clinical findings

Since most of iron in the body is utilized for synthesis of hemoglobin, the most crucial searching for of iron shortage is anemia. In iron shortage anemia, clinical searchings for second 
to anemia could be located as in all anemias or the medical diagnosis could be made during laboratory examinations in the absense of any clinical finding. Gradually proceeding paleness might in some cases be missed by families. The clinical searchings for observed in iron shortage anemia are summed up in Table 1. The searching for which is primarily highlighted in iron shortage anemia is its impacts on the neurocognitive system. Numerous properly designed possible studies have revealed that motor and cognitive retardation and mood disorders could be observed in children with iron shortage ${ }^{[5-7]}$. Lozoff et al. ${ }^{[8]}$ revealed that children with iron shortage obtained tired extra quickly, played much less and were more hesitant contrasted to completely healthy youngsters. A lot more significantly, these results persisted 10 years after treatment ${ }^{[9]}$. ID which has advanced to iron deficiency anemia might create to interruption in mental and motor functions and these impacts might be irreversible. The system of action by which iron deficiency creates to neurocognitive disorders is not completely comprehended. In some studies, it was revealed that ID decreased expression of dopamin receptors, disrupted myelinization or interrupted the function of various enzymes involved in the nerve tissue ${ }^{[10-}$ 12]. Once more, an additional important yet questionable clinical result of iron deficieny is its effects on the body immune system ${ }^{[13-15]}$. Furthermore, it was revealed that IDA was strongly connected with febrile convulsions in some recent researches and in a meta-analysis done in $2010^{[17,16]}$.

\section{- Diagnosis and laboratory findings}

In medicine, a detailed background and checkup is necessary in the medical diagnosis of all diseases as a general regulation. In one study, it was shown that anemia could be identified with a detailed history with a sensitivity of $71 \%$ and specificity of $79 \%{ }^{[18]}$. Especially prenatal period, nourishment, times of starting bust milk and strong foods and bleeding history ought to be questioned in information. Signs of anemia and various other systemic diseases which could accompany must be looked for. The laboratory examinations which might be used are summed up in Table 2 .

Table 1. Iron deficiency findings

\begin{tabular}{|l|l|}
\hline Skin & Nails \\
Pallor & Koilonychia \\
\hline
\end{tabular}

\begin{tabular}{|c|c|}
\hline $\begin{array}{l}\text { Musculoskletal system } \\
\text { Decreased effort capacity } \\
\text { Exercise limitation }\end{array}$ & $\begin{array}{l}\text { Increased absorption of } \\
\text { heavy metals } \\
\text { Lead intoxication }\end{array}$ \\
\hline $\begin{array}{l}\text { Cardiovascular system } \\
\text { Increased cardiac output } \\
\text { Tachycardia } \\
\text { Cardiomegaly } \\
\text { Heart failure }\end{array}$ & $\begin{array}{l}\text { Gastrointestinal system } \\
\text { Loss of appetite } \\
\text { Angular stomatitis } \\
\text { Atrofic glossitis } \\
\text { Dysphagia Pica } \\
\text { Gluten sensitive } \\
\text { enteropathy } \\
\text { Plummer-Vinson } \\
\text { syndrome }\end{array}$ \\
\hline $\begin{array}{l}\text { Central nervous system } \\
\text { Irritability-malaise } \\
\text { Fainting } \\
\text { Papilledema } \\
\text { Pseudotumor cerebri } \\
\text { 6th nerve palsy } \\
\text { Restless leg syndrome } \\
\text { Breath holding spell } \\
\text { Sleep disturbance } \\
\text { Attention deficit } \\
\text { Learning difficulty } \\
\text { Behavioral disorder } \\
\text { Decrease in perception } \\
\text { functions } \\
\text { Retardation in motor and } \\
\text { mental developmental } \\
\text { tests }\end{array}$ & $\begin{array}{l}\text { Immune system } \\
\text { disorders } \\
\text { Decreased resistance } \\
\text { against infections } \\
\mathrm{T} \text { lymphocyte and } \\
\text { polymorphonuclear } \\
\text { leukocyte dysfunction }\end{array}$ \\
\hline
\end{tabular}

The primary activity is ordering complete blood count and peripheral blood smear. When complete blood matter is evaluated well, it may offer lots of clues in the medical diagnosis of many diseases of the childhood ${ }^{[19]}$. In total blood count, it needs to be mostly checked if hemoglobin and hematocritt worths are regular for age and gender (if anemia exists). The lower restrictions of regular by age and gender specified by the World Health Organization may be made use of, since they are practical and values below these limitations are thought about anemia (Table 3). In babies younger compared to 6 months, lower worths are observed as a result of physical anemia, however hemoglobin is not anticipated to be reduced than $9 \mathrm{~g} / \mathrm{dL}$ in physiological anemia in term babies if there is no various other coming with aspect.

Erythrocytes show up pale and smaller compared to regular when the amount of hemoglobin in is lowered. This appears by decreased mean erythrocyte volume (MCV) and minimized mean eryhtrocyte hemoglobin $(\mathrm{MCH})$ in total blood matter. On peripheral blood smear, the erythrocytes are microcytic and hypochromic. 
Table 2. Investigations which may be oredered in patients in whom iron deficiency is considered

\begin{tabular}{|c|}
\hline $\begin{array}{ll}\text { - } & \text { Complete blood count } \\
\text { - } & \text { Peripheral blood smear } \\
\text { - } & \text { Reticulocyte } \\
\text { - } & \text { Urea, creatinine } \\
\text { - } & \text { Serum iron, total iron binding capacity, } \\
\text { transferrin saturation index } \\
\text { - } \quad \text { Ferritin } \\
\text { - } & \text { Serum soluble transferrin receptor level } \\
\end{array}$ \\
\hline
\end{tabular}

Table 3. Lower limits for hemoglobin and hematoctrit values specified by the World Health Organization by age and gender

\begin{tabular}{|l|l|l|}
\hline $\begin{array}{l}\text { Groups by } \\
\text { age } \\
\text { gender }\end{array}$ & Hemoglobin(g/dL) & $\begin{array}{l}\text { Hematocrit } \\
(\%)\end{array}$ \\
\hline $\begin{array}{l}\text { Children aged } \\
\text { between 6-59 } \\
\text { months }\end{array}$ & 11 & 33 \\
\hline $\begin{array}{l}\text { Children aged } \\
\text { between 5-11 } \\
\text { years }\end{array}$ & 11.5 & 34 \\
\hline $\begin{array}{l}\text { Children aged } \\
\text { between 12-14 } \\
\text { years }\end{array}$ & 12 & 36 \\
\hline $\begin{array}{l}\text { Girls aged >15 } \\
\text { years }\end{array}$ & 12 & 36 \\
\hline $\begin{array}{l}\text { Boys aged } \\
>15 \text { years }\end{array}$ & 13 & 39 \\
\hline
\end{tabular}

Mean erythrocyte volume and $\mathrm{MCH}$ are identical to each various other; this implies that microcytic erythrocytes are hypochromic at the very same time. If the $\mathrm{MCH}$ is below $27 \mathrm{pg}$, it is reduced. The regular value of mean erythrocyte quantity varies in between 80 and $99 \mathrm{fL}$, yet regular values by age ought to be considered in youngsters. Formulas which might be made use of merely in busy outpatient clinical practice are additionally existing (Table 4). Here, it is important to utilize the formula for the reduced limitation for children more youthful compared to 10 years, due to the fact that the reduced limit is $80 \mathrm{fL}$ in kids older compared to 10 years as in grownups.

In anemias related with dietary deficiencies, there is a non-homogeneous erythrocyte volume as opposed to congenital anemias consisting of thalassemia; erythrocytes may have variable dimensions inning accordance with the amount of hemoglobin. This is shown by anisocytosis on peripheral smear and by increased erythrocyte distribution width (RDW) on blood count. Basically, nutritional deficiency needs to be taken into consideration, if enhanced RDW together with anemia is existing; if reduced MCV is likewise existing, iron shortage is taken into consideration and if increased MCV is existing, vitamin B12 or folic acid shortage may exist.

Table 4. Laboratory findings in iron deficiency

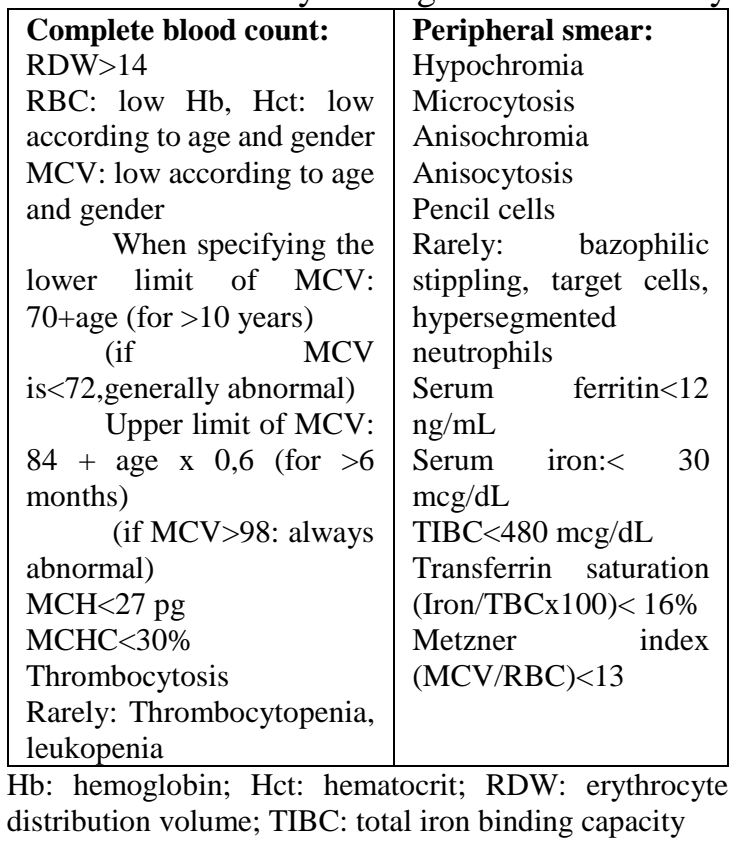

However, it should be maintained in mind that withdrawal or shortage anemia where all variables are disrupted is not observed hardly ever in the majority of kids with malnutrition. A normal RDW worth and microcytosis recommend thalassemia carrier state instead of iron shortage anemia. Generally, 2 separate RDW outcomes are noted in complete blood matter results; RDW-CV and RDW-SD. This arises from a statistical calculation difference. RDW-SD is the conventional discrepancy of the erythrocyte and is the mean of inconsistencies from MCV of each erythrocyte; its normal variety is $37-54 \mathrm{fL}$. RDW-CV is the variability coefficient of erythrocyte circulation quantity and the percent expression of the basic variance by mean erythrocyte volume. RDW$\mathrm{CV}$ is an extra trusted dimension and is abnormal if it is $>14$. Furthermore, erythrocyte distribution width is the very first variable which alters in total blood matter in iron deficiency anemia. In parallel, the very first searching for of IDA on outer smear is anisocytosis.

On top of that, thrombocytosis in connection with IDA may be observed in full blood matter. The factor of thrombocytosis is cross-reaction of enhanced erythropoietin in IDE with thrombopoetin receptors in the megakaryocytes 
which brings about raised platelet matter. Although hardly ever, thromobocytopenia could likewise be observed in IDA ${ }^{[20]}$. The leukocyte count is generally normal, but leukopenia could also be observed. However, other diagnoses must be thought about mostly in cases of anemia particularly come with by leukopenia and/ or thrombocytopenia. Eosinophilia in full blood matter or outer smear may offer a clue in terms of underlying parasitosis. At this factor, treatment can be begun straight, if full blood matter and peripheral smear highly suggest IDA. If there is uncertainty, treatment itself is an excellent diagnostic device. However, getting iron variables at the standard is a much better scientific method; further it will certainly be useful for differential diagnosis and if anemia will not reply to iron therapy. Actually, hemogram may suffice in the diagnosis of IDA, but it could be normal in the onset of iron shortage. Iron shortage creates in the body in three stages.

1. Prelatent stage: Iron stores are lowered or absent, serum iron concentration, hemoglobin and hematocrit are normal. This stage of iron deficiency is manifested with reduction or absence of bone marrow iron stores and reduced serum ferritin level.

2. Latent stage: serum iron (SI) and transferrin saturation are reduced in addition to reduced iron stores. Hemoglobin and hemoctrit are within normal limits.

3. Marked IDA: In addition to the depletion of iron stores, serum iron and transferrin saturation hemoglobulin and hematocrit levels are reduced.

All variables may not change at the same time due to advancement of these phases in children with iron deficiency. One need to be really mindful when assessing iron variables. The serum ferritin level is the very best sign of the iron stores in the body and the first biochemical variable to change in ID. A serum ferritin degree below 10-12 $\mu \mathrm{g}$ / L strongly sustains ID, however ferritin is an acute phase reactant and it need to be maintained in mind that it might be enhanced in infection and inflammation. Plasma iron is decreased as the iron in the body is worn down. Examples must be obtained in the early morning after one- night fasting, since its worth shows variation during the day time and is affected by diet regimen. Plasma iron degree is not valuable in the differential diagnosis from IDA due to the fact that it is likewise minimized in anemia of chronic illness. Iron binding capacity (complete iron binding capacity-TIBC) increased as serum iron reduces. The worth acquired by separating the serum iron value to TIBC shows transferrin saturation and is reduced in ID. Iron and TIBC are also acute stage reactants and rise in inflammation/infection.

\section{- IDA Treatment}

Successful treatment of IDA depends on three essential steps:

1. Iron therapy

2. Dietary changes

3. Lab monitoring for assessment of response

\section{Iron Therapy}

Oral iron therapy is finest administered as oral ferrous sulphate as it is the a lot of budgetfriendly. Dosage is $3-6 \mathrm{mg} / \mathrm{kg} / \mathrm{d}$ of important iron (maximum is $150 \mathrm{mg}$ ). A dose of $3 \mathrm{mg} / \mathrm{kg}$ is sufficient for treatment and this dosage is also related to fewer negative impacts. For optimal absorption, iron ought to be given between meals and with vitamin $\mathrm{C}$ consisting of juice as opposed to milk. A reticulocyte action is seen in $72 \mathrm{~h}$ and hemoglobin should increase by 1 $\mathrm{g} / \mathrm{dl}$ in $1 \mathrm{mo}$. Other ferrous salts like ferrous fumarate and ferrous gluconate may be used; the dose of essential iron stays the exact same but the amount of important iron varies from one salt to one more. Ascorbate combined with iron boosts iron absorption but this advantage is nullified because of the higher occurrence of negative impacts ${ }^{[21]}$. Heme based prep work, ferric ammonium citrate and iron polymaltose facility may be much less effective. Gastrointestinal signs and symptoms like irregularity and diarrhea are uncommon with iron preparations at the dosages mentioned above. Grey staining of teeth is seen with fluid prep work and is temporary. This could be minimised by brushing the teeth and rinsing mouth with water after management of the liquid prep work. All kids with IDA need to also be offered anthelminthic.

\section{Dietary Changes}

Bottle feeding leads to consumption of huge amount of milk ${ }^{[22]}$. Eliminating the container is an important initial step in the treatment. Unmodified cow's milk need to be avoided under $1 \mathrm{y}$ of age and if inescapable as a result of failure of breast feeding and absence of 
affordability of formula feed, it is necessary to offer iron supplementation and monitor for IDA. For children greater than 1 y of age, milk consumption should not be greater than 500 $\mathrm{ml} / \mathrm{d}$. Consumption of iron abundant food should be encouraged.

\section{Monitoring Response}

A repeat $\mathrm{CBC}$ after 1 month of iron therapy ought to show a rise in hemoglobin by $1 \mathrm{~g} / \mathrm{dl}$. Confirm normalisation of hemoglobin (as each age adjusted normal values) by repeating a CBC every 2-3 month and proceed iron supplementation for a more 3 month after normalisation of hemoglobin to replenish the storage space swimming pool.

Reasons for Lack of Response to Iron Therapy

Nonresponders, those who do not respond to iron could fall in one of two categories:

1. Hypochromic microcytic anemia but not IDA: Thalassemia trait and ACD

2. IDA but recurrent or refractory:

- Poor compliance to medications or to dietary advice.

- Overt/occult gastrointestinal blood loss, e.g., cow milk protein induced colitis

- Parasitic infestation

- Meckel's diverticulitis

- Celiac disease

- Pulmonary hemosiderosis (occult/overt blood loss in lungs)

- Inflammatory bowel disease

- Rare mutations of iron transport

For the second group, further investigations like stool for occult blood, endoscopy for evidence of upper/lower gastrointestinal bleed, and tissue transglutaminase antibodies (TTG) to rule out celiac disease are recommended.

Conclusion:

Conclusively, iron deficiency anemia continues to be a considerable public health issue worldwide. The major concepts in treatment of iron deficiency anemia consist of making the diagnosis, investigating the condition which triggers to iron deficiency and removal of this problem, replacement of deficiency, enhancement of nutrition and education of patients and families. The serum ferritin level is the best indicator of the iron stores in the body and the first biochemical variable to change in ID. Enhancing intake of meat and meat products is very essential in prevention and treatment of iron deficiency. The various other foods rich in iron include egg, well-done legumes, green vegetables and dry fruit.

\section{Reference:}

1. World Health Organization (2001): Iron deficiency anaemia assessment, prevention, and control. A guide for programme managers. Geneva (Switzerland): World Health Organization.

http://www.who.int/nutrition/publicati ons/micronutrients/anaemia_iron_defi ciency/WHO_NHD_01.3/en/

2. Brittenham GM (2005): Disorders of iron metabolism: Iron deficiency and overload. In: Hoffman R, Benz Jr EJ, Shattil SJ, editors. Hematology Basic Principles and Practice. 4th ed. New York: Churchill Livingstone.

3. Conrad ME and Umbreit JN (2000): Iron absorption and transport-an update. Am J Hematol., 64:287-98.

4. Gür E, Yıldız I, Celkan T (2005): Prevalence of anemia and the risk factors among school children in İstanbul. J Trop Pediatr., 51: 346-50.

5. Oski FA (1979): The nonhematologic manifestations of iron deficiency. Am J Dis Child., 133: 315-22.

6. Oski FA, Honig AS, Helu B et al. (1983): Effect of iron therapy on behavior performance in nonanemic, iron deficient infants. Pediatrics, 71: 877-80.

7. Akman M, Cebeci D, Okur V et al. (2004): The effects of iron deficiency on infants' developmental test performance. Acta Paediatr., 93: 13916.

8. Lozoff B, Klein NK, Nelson EC et al. (1998): Behavior of infants with iron deficiency anemia. Child Dev., 69: 2436.

9. Lozoff B, Jimenez E, Hagen J et al. (2000): Poorer behavioral and developmental outcome more than 10 years after treatment for iron deficiency in infancy. Pediatrics, 105: E51.

10. Erikson KM, Jones BC, Hess EJ et al. (2001): Iron deficiency decreases dopamine $D(1)$ and $D(2)$ receptors in rat brain. Pharmacol Biochem Behav., 69: 409-18.

11. Ortiz E, Pasquini JM, Thompson K et al. (2004): Effect of manipulation of 
iron storage, transport, or availability on myelin composition and brain iron content in three different animal models. J Neurosci Res., 77: 681-9.

12. Beard JL (2001): Iron biology in immune function, muscle metabolism and neuronal functioning. J Nutr.,131: 568S-579S.

13. Eddison ES, NBajel $A$ and Chandy $M$ (2008): Iron homeostasis: new players, newer insights. Eur $\mathbf{J}$ Haematol., 81: 411-24.

14. Chandra RK and Saraya AK (1975): Impaired immunocompetence associated with iron deficiency. $J$ of Pediatr., 86: 899-902.

15. Joynson DH, Walker DM et al. (1972): Defect of cell mediated immunity in patients with iron deficiency anaemia. Lancet, 2: 1058-9.

16. Idro R, Gwer S, Williams TN et al. (2010): Iron deficiency and acute seizures: results form children living in rural Kenya and a meta-analysis. PloS One, 5:14001-14006.

17. Kig D and Kİng A (2014): Question 2: Should children who have a febrile seizure be screened for iron deficiency? Arch Dis Child., 99: 960-4.
18. Boutry $M$ and Needlman $R$ (1996): Use of diet history in the screening of iron deficiency. Pediatrics, 98: 113842.

19. Yıldız İ (2001): Kan sayımında otomasyon parametreleri. İ.Ü. Cerrahpaşa Tıp Fakültesi sürekli tıp eğitimi etkinlikleri: anemiler sempozyumu.

https://www.researchgate.net/publicati on $/ 276901770$

20. Ozdemir N, Celkan T, Kebudi $\mathrm{R}$ et al. (2011): Cytopenia associated with iron deficiency anemia and iron therapy: a report of two cases. Turk J Haematol., 28, 243-4.

21. Hallberg $L$, Brune $M$ and Rossander L (1986): Effect of ascorbic acid on iron absorption from different types of meals. Studies with ascorbic acid rich foods and synthetic ascorbic acid given in different amounts with different meals. Hum Nutr Appl Nutr., 40:97.

22. Sutcliffe TL, Khambalia A, Westergard $S$ et al. (2006): Iron depletion is associated with daytime bottle-feeding in the second and third years of life. Arch Pediatr Adolesc Med., 160:1114-20. 